\title{
Does the Implant Selection Affect the Mortality Rate in Elderly Intertrochanteric Fix?
}

\author{
Saberi Masoud* \\ Consultant at Loghman General Hospital, Iran \\ *Corresponding author: Saberi Masoud, Orthopedic Surgeon, Consultant at Loghman General Hospital, Iran
}

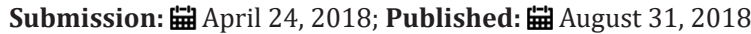

\begin{abstract}
Objective: We thought the stable implant construction may affect outcome for elderly hip fracture so assessed the patients for one year as a consecutive prospective study.

Method: We include 83 patients. all above 60 years old patients who came to our center with unstable intertrochanteric fracture in one-year admission at the end we assess the mortality rate and compared with other study.

Conclusion: It seems stable implant has a little role in mortality rate but in one year follow up we had $24 \%$ mortality and $50 \%$ readmission because comorbidity exacerbated which compare to other studies had no deference $(\mathrm{p}<0.01)$
\end{abstract}

\section{Introduction}

Opponents of nonoperative treatment for non-ambulatory patients suggest that surgery is more effective for pain relief and does not result in unacceptable increased mortality or complications. Ambulatory capability with nonoperative treatment was usually viewed as poor, however some patients do regain some degree of ambulation ability [1]. Although there is no new evidence, prior projection studies indicate that by 2050 , the number of hip fracture incidence could increase to between 4.5 and 6.5 million per year around the world [1-3].

Since 1950s when introducing surgery for treatment of hip fracture the goal of surgery from save limb and set union changes to achieving well functional outcome. Keene et al. [4] Found that higher mortality and morbidity in hip fracture was because of baseline comorbidity in these patients [3] and another study were found mortality is not direct related to surgery [4]. According to AAOS guideline surgery as a first-choice treatment well accepted worldwide and the design of implants for fixation have well improving. An intramedullary fixed angel devices for treatment of unstable intertrochanteric fracture had better outcomes [5].

\section{Method}

After searching data base like Medline there is few studies which assesses a relationship between mortality and stable device have been found, conversely, we thought it maybe exist so design this study stablished. We include all unstable extra-capsular acute hip fracture in patients above 60 years old who brought to our hospital for one year and underwent surgery with helical blade short femoral nails. Before surgery all patient sent for cardiac test and any other test if he/she suffered before admission, all optimization was done in 3-5 days. Reduction was done by traction table closely and nailing was done per cutaneous by one design. All the surgeries done by one well experienced Orthopeadic surgeon.

\section{Results}

Total number of patients were 83 . about 49 women and 34 man. After one year we assessed mortality rate As we got, $24 \%$ (20 patients) mortality rate after one year and 6\% (3 man and 2 women) death in first month. Of this number (20 patients) 12 were women (14.4\%) and 8 were man (9.6\%) (Figure 1-4).

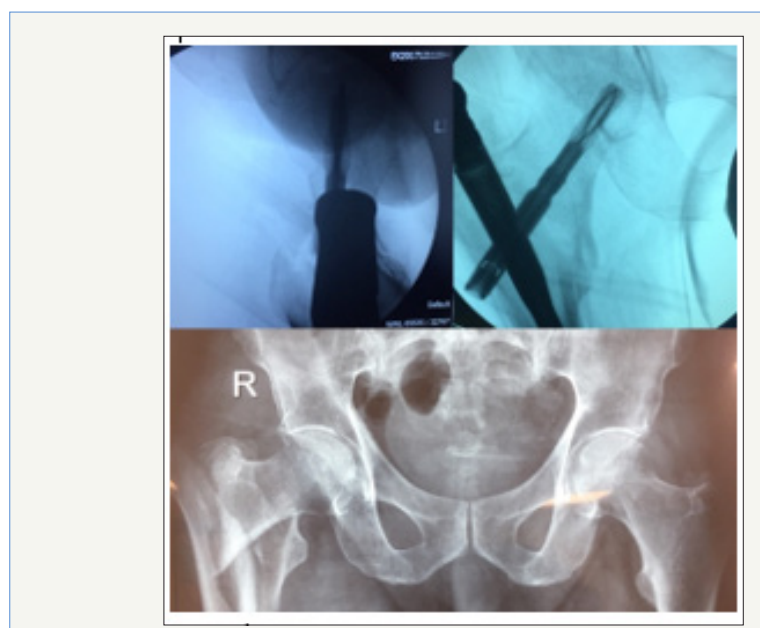

Figure 1: OTA/31A3. 


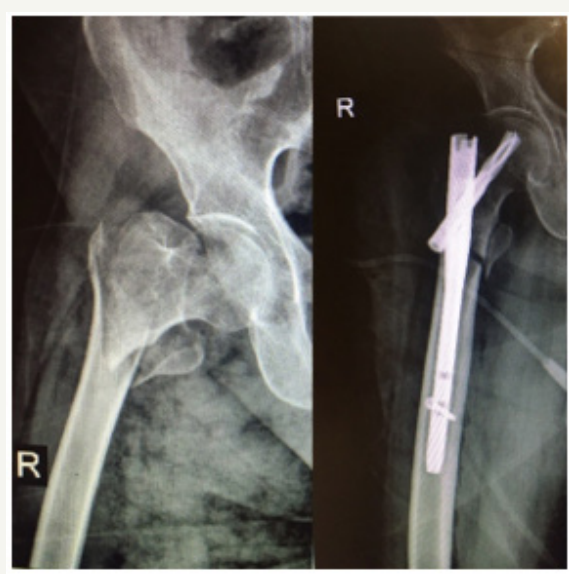

Figure 2: OTA/31A2.

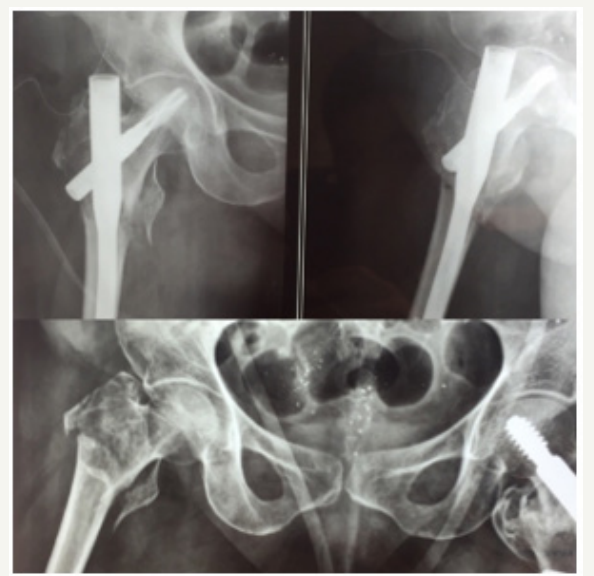

Figure 3: OTA/31A2.

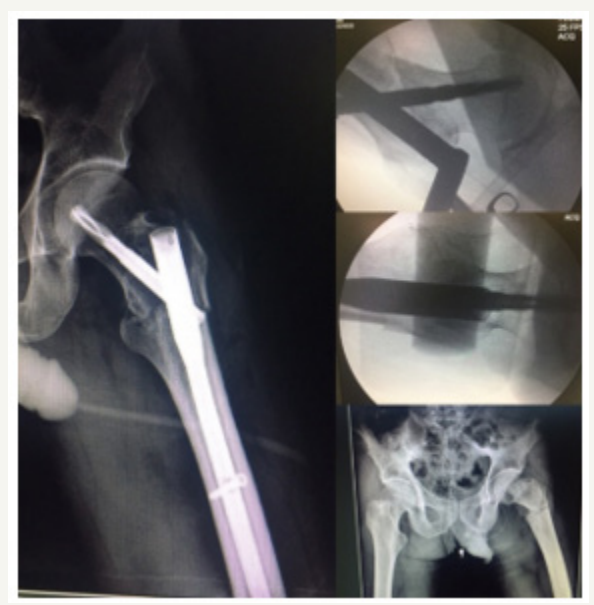

Figure 4: OTA/31A3.

\section{Conclusion}

The risk of implant selection which affect in functional outcomes seems logical and have many studies on back but for mortality maybe represented not that. Overall, mortality seems to be highest in men, nursing home residents, patients older than
90 years, patients treated nonsurgical, patients with significant cognitive impairment or comorbidities, and patients who are unable to ambulate independently [6-8]. Authors of one study noted that patients with intertrochanteric fractures were sicker at baseline, with greater comorbidities, and thus may have higher morbidity and mortality rates [3].

Overwhelming of rigid construct fixation is according to many studies which have better functional outcome after nailing compare to side plating. Patients who underwent intramedullary nail procedures had a shorter length of stay by 1.0 day $(\mathrm{P}<0.001)$, but no other outcome of adverse events, readmission, or operating room time showed any difference between the two groups [5]. Oneyear mortality rates have been reported to be as wide ranging as $12 \%$ to $37 \%$ [9-11]. According to Nationwide Inpatient Sample data from 2005, the in-hospital death rate after hip fracture was $2.8 \%$ [12]. However, hip fractures in general substantially increase the risk of death in elderly patients. A meta-analysis of prospective studies found relative hazard rates form mortality during the first 3 months after hip fracture to be a relative risk of 5.75 in women and of 7.95 in men [13].

In a prospective trial in which they compared nailing with plating for stable intertrochanteric hip fractures, the authors found significant loss of function in the first 6 months in the plate group. However, they found no difference in functional scores at 1 year. The mortality rates and complications rates were similar [14]. As we got there is no deference in mortality after one year in hip fractures and comorbidity risk factors may have a stronger than implant for mortality prevention [15]. Last but not least, prevention of falling in well developed country seems have a potent evidence for overall diminishing of number of deaths in this population.

\section{References}

1. Handoll HH, Parker MJ (2008) Conservative versus operative treatment for hip fractures in adults. Cochrane Database Syst Rev (3): CD000337.

2. Cooper C, Campion G, Melton LJ (1992) Hip fractures in the elderly: A world-wide projection. Osteoporos Int 2(6): 285-289.

3. Gullberg B, Johnell O, Kanis JA (1997) World-wide projections for hip fracture. Osteoporos Int 7(5): 407-413.

4. Keene GS, Parker MJ, Pryor GA (1993) Mortality and morbidity after hip fractures. BMJ 307(6914): 1248-1250.

5. Parker MJ, Handoll HH (2000) Conservative versus operative treatment for extracapsular hip fractures. Cochrane Database Syst Rev (2): CD000337.

6. Bohl DD, Basques BA, Golinvaux NS, Miller CP, Baumgaertner MR, et al. (2014) Extramedullary compared with intramedullary implants for intertrochanteric hip fractures: Thirty-day outcomes of 4432 procedures from the ACS NSQIP database. J Bone Joint Surg Am 96(22): 1871-1877.

7. Frost SA, Nguyen ND, Black DA, Eisman JA, Nguyen TV (2011) Risk factors for in-hospital post-hip fracture mortality. Bone 49(3): 553-558.

8. Alzahrani K, Gandhi R, Davis A, Mahomed N (2010) In-hospital mortality following hip fracture care in southern Ontario. Can J Surg 53(5): 294298.

9. Mariconda M, Costa GG, Cerbasi S, Recano P, Aitanti E, et al. (2015) The determinants of mortality and morbidity during the year following fracture of the hip: A prospective study. Bone Joint J 97(3): 383-390. 
10. Wolinsky FD, Fitzgerald JF, Stump TE (1997) The effect of hip fracture on mortality, hospitalization and functional status: A prospective study. Am J Public Health 87(3): 398-403.

11. Panula J, Pihlajamäki H, Mattila VM, Jaatinen P, Vahlberg T, et al. (2011) Mortality and cause of death in hip fracture patients aged 65 or older: A population-based study. BMC Musculoskelet Disord 12: 105.

12. Le Blanc ES, Hillier TA, Pedula KL, et al (2011) Hip fracture and increased short-term but not long-term mortality in healthy older women. Arch Intern Med 171(20): 18311837.
13. Haentjens P, Magaziner J, Colón-Emeric CS, et al (2010) Meta-analysis: Excess mortality after hip fracture among older women and men. Ann Intern Med 152(6): 380-390

14. Guerra MT, Pasqualin S, Souza MP, Lenz R (2014) Functional recovery of elderly patients with surgically-treated intertrochanteric fractures: Preliminary results of a randomised trial comparing the dynamic hip screw and proximal femoral nail techniques. Injury 45(5): S26-S31.

15. Russo A, Owens PL, Stocks C (2004) Agency for healthcare research and quality: Common injuries that result in hospitalization. Healthcare Cost and Utilization Project, USA.

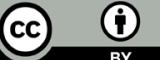

Creative Commons Attribution 4.0 International License

For possible submissions Click Here
Submit Article

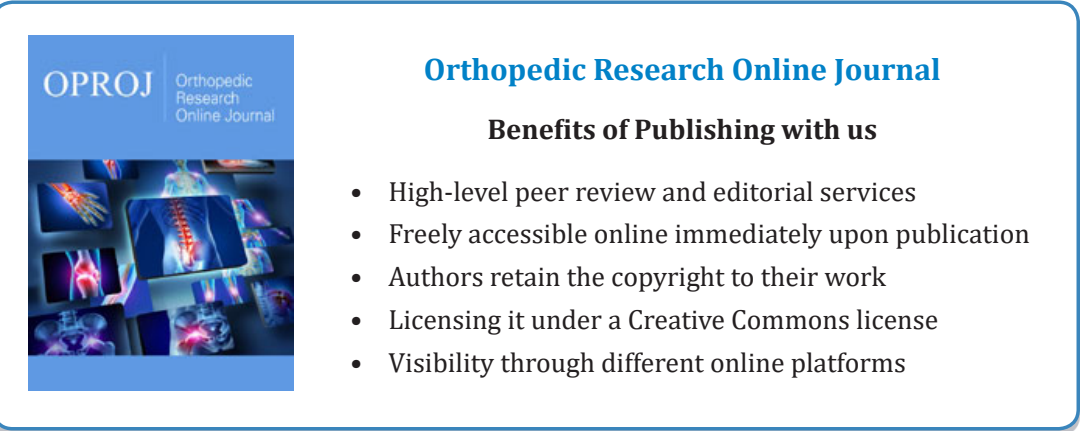

